06.1

\title{
Влияние термообработки на свойства композитных кремний-углеродных анодов для литий-ионных аккумуляторов
}

\author{
(C) Е.В. Астрова, А.В. Парфеньева, А.М. Румянцев, В.П. Улин, М.В. Байдакова, В.Н. Неведомский, \\ A.B. Нащекин
}

Физико-технический институт им. А.Ф. Иофффе РАН, Санкт-Петербург, Россия

E-mail: east@mail.ioffe.ru

Поступило в Редакцию 10 октября 2019 г.

В окончательной редакции 30 октября 2019 г.

Принято к публикации 30 октября 2019г.

\begin{abstract}
Проведено исследование влияния температуры отжига в атмосфере аргона на способность нанокомпозитов $\mathrm{Si}-\mathrm{C}$ обратимо внедрять литий. Установлено, что чем выше температура отжига при формировании композита, тем ниже емкость изготовленного из него электрода. С помощью рентгеноструктурного анализа и просвечивающей электронной микроскопии показано, что причиной снижения емкости является образование при $T \geqslant 1100^{\circ} \mathrm{C}$ карбида кремния кубической модификации $\beta$ - $\mathrm{SiC}$, неактивного по отношению к образованию литиевых сплавов или интеркалятов.
\end{abstract}

Ключевые слова: литий-ионные аккумуляторы, анодные материалы, кремний-углеродные композиты, карбид кремния.

DOI: 10.21883/PJTF.2020.03.48985.18067

В последние годы активно ведутся работы по поиску новых электродных материалов для разработки литий-ионных аккумуляторов нового поколения. Для отрицательных электродов наибольший интерес представляют кремний-углеродные нанокомпозиты, которые могут обеспечить высокие значения емкости, скорости перезарядки и циклического ресурса [1]. Предложены различные способы получения таких композитов, при которых побочным продуктом может быть карбид кремния [2]. До недавнего времени существовало общее мнение о том, что Li не способен внедряться в карбид кремния [3], и при изготовлении композитных анодов $\mathrm{Si}-\mathrm{C}$ старались избегать образования $\mathrm{SiC}$ [4]. Однако в некоторых работах [5-7] это мнение было подвергнуто сомнению. Так, в работе [6] утверждается, что $\mathrm{SiC}$ в виде наночастиц способен интеркалировать литий, а в работе [7] указывается на то, что образование карбида кремния способствует повышению циклического времени жизни композита $\mathrm{Si}-\mathrm{C}$. В нашей работе [8] было предложено формировать кремний-углеродные нанокомпозиты путем карбонизации кремния, происходящей при термическом восстановлении монофторида углерода при $T=800^{\circ} \mathrm{C}$. Полученные материалы представляют собой иерархическую пористую структуру, состоящую из кремниевых наночастиц, заключенных в оболочку из мелкодисперсного углерода. Изготовленные из них аноды на начальных циклах демонстрируют падение емкости, которое на последующих циклах прекращается, и емкость стабилизируется. Установившееся значение их удельной гравиметрической емкости примерно на 40\% превышает емкость традиционных углеродных электродов.
В настоящей работе ставилась задача изучить влияние отжига на электрохимические характеристики и фазовый состав таких электродов $\mathrm{Si}-\mathrm{C}$.

Прекурсорами для формирования нанокомпозита служили нанопорошок $\mathrm{Si}$, состоящий из кристаллических частиц диаметром 30-50 nm (Hongwu Nanometer Company, China), и порошок фторуглерода $\mathrm{CF}_{x}$, где $x=0.82$, с зернами размером $0.3-5 \mu \mathrm{m}$ (Halo Polymer). Эти порошки смешивались и тщательно измельчались в агатовой ступке. Содержание $\mathrm{CF}_{x}$ в исходной смеси составляло 60-75 wt.\%. Из полученной смеси путем холодного сухого прессования при давлении $180 \mathrm{MPa}$ формировались таблетки диаметром $10 \mathrm{~mm}$ и толщиной $\sim 650 \mu \mathrm{m}$. Эти таблетки подвергались отжигу в атмосфере чистого Ar путем нагрева от 400 до $800^{\circ} \mathrm{C}$ со скоростью $3.3^{\circ} \mathrm{C} / \mathrm{min}$. Подробности технологии приведены B $[8]$.

В процессе этого низкотемпературного отжига происходила реакция восстановления фторуглерода с образованием газообразного $\mathrm{SiF}_{4}$ и аморфного углерода. Суммарную реакцию можно записать как

$$
(4 / x) \mathrm{CF}_{x}+\mathrm{Si}=\mathrm{SiF}_{4} \uparrow+(4 / x) \mathrm{C},
$$

где $x=0.82$. Массовая доля кремния $m$ (в wt.\%) в твердой фазе готового композита может быть найдена как [8]:

$$
m=(100-1.208 r) /(100-0.773 r),
$$

где $r$ - массовая доля $\mathrm{CF}_{x}($ в \%) в исходной смеси порошков. Для получения композита $\mathrm{Si}-\mathrm{C}$ (карбонизации кремния) кремний должен быть в избытке. Для этого 

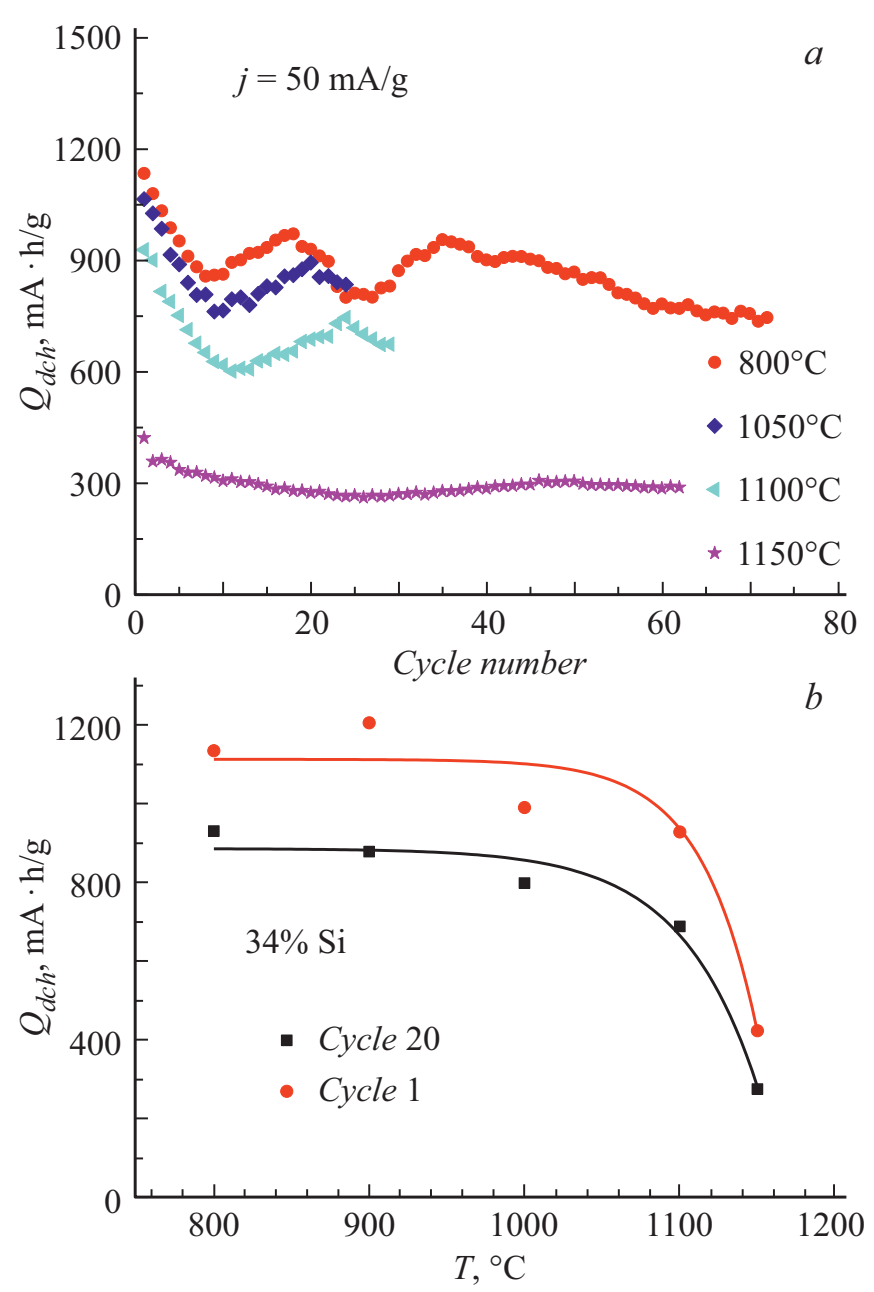

Рис. 1. Зависимости разрядной емкости композитных анодов $\mathrm{Si}-\mathrm{C}(34 \% \mathrm{Si})$ от номера цикла до $\left(800^{\circ} \mathrm{C}\right)$ и после $\left(1050-1150^{\circ} \mathrm{C}\right)$ дополнительного отжига $(a)$ и от температуры дополнительного отжига для циклов 1 и $20(b)$.

необходимо, чтобы в исходной смеси его содержание было $>17.2 \%$. Дополнительный высокотемпературный отжиг полученных композитных таблеток при $T=1150^{\circ} \mathrm{C}$ в $\mathrm{Ar}$ в течение часа приводил к небольшому увеличению их плотности и небольшому снижению удельного электрического сопротивления (от 0.55 до $0.59 \mathrm{~g} / \mathrm{cm}^{3}$ и от 0.35 до $0.3 \Omega \cdot \mathrm{cm}$ для композитной таблетки c $34 \% \mathrm{Si})$.

Для проведения электрохимических испытаний таблетки $\mathrm{Si}-\mathrm{C}$ утоньшались до $\sim 75 \mu \mathrm{m}$, приклеивались на медную фольгу тонким слоем пасты на основе поливинилиденфторида (PVDF), высокорасщепленного графита и NMP (N-метилпирролидона) и вырезались по диаметру ячейки. Электроды диаметром $15 \mathrm{~mm}$ монтировались в двухэлектродную дисковую ячейку CR2032 с литиевым противоэлектродом. В качестве электролита использовался ТC-E918 (Tinci), представляющий собой $1 \mathrm{M}$ раствор $\mathrm{LiPF}_{6}$ в смеси органических карбонатов.
Измерения проводились в гальваностатическом режиме с использованием стенда CT3008W-5V10mA (Neware). Заряд и разряд осуществлялись при плотности тока $j=50 \mathrm{~mA} / \mathrm{g}$. Внедрение Li (в наших терминах заряд) происходило до тех пор, пока напряжение на испытываемом электроде не упадет до $10 \mathrm{mV}$, а экстракция (разряд) - до достижения потенциала $2 \mathrm{~V}$.

На рис. 1, $a$ показано, как по мере увеличения числа циклов заряда-разряда изменяется разрядная емкость $Q_{d c h}$ образцов, изготовленных из исходной смеси порошков $30 \% \mathrm{Si}+70 \% \mathrm{CF}_{x}$ и отожженных при разной температуре. В соответствии с (2) в композите, полученном из этой смеси, доля кремния составляет $m=34 \%$. При электрохимическом литировании углерод образует соединение состава $\mathrm{LiC}_{6}$, что соответствует удельной гравиметрической емкости $Q_{\mathrm{C}}=375 \mathrm{~mA} \cdot \mathrm{h} / \mathrm{g}$, а кремний - соединение $\mathrm{Li}_{3.75} \mathrm{Si}$, для которого $Q_{\mathrm{Si}}=3616 \mathrm{~mA} \cdot \mathrm{h} / \mathrm{g}$. Емкость композитного материала $\mathrm{Si}-\mathrm{C}$, содержащего $m$ весовых долей $\mathrm{Si}$, должна быть равна $Q_{\text {mix }}=3241 m+375[\mathrm{~mA} \cdot \mathrm{h} / \mathrm{g}]$. Таким образом, ожидаемая емкость для анода, содержащего $34 \% \mathrm{Si}$, составляет $Q=1477 \mathrm{~mA} \cdot \mathrm{h} / \mathrm{g}$. Из рисунка видно, что начальное значение $Q_{d c h}$ несколько меньше ожидаемого. Кроме того, на первых 10-15 циклах наблюдается снижение емкости, и только затем она выходит на „полочку“. Наблюдаемое на графике отклонение от постоянного значения в области
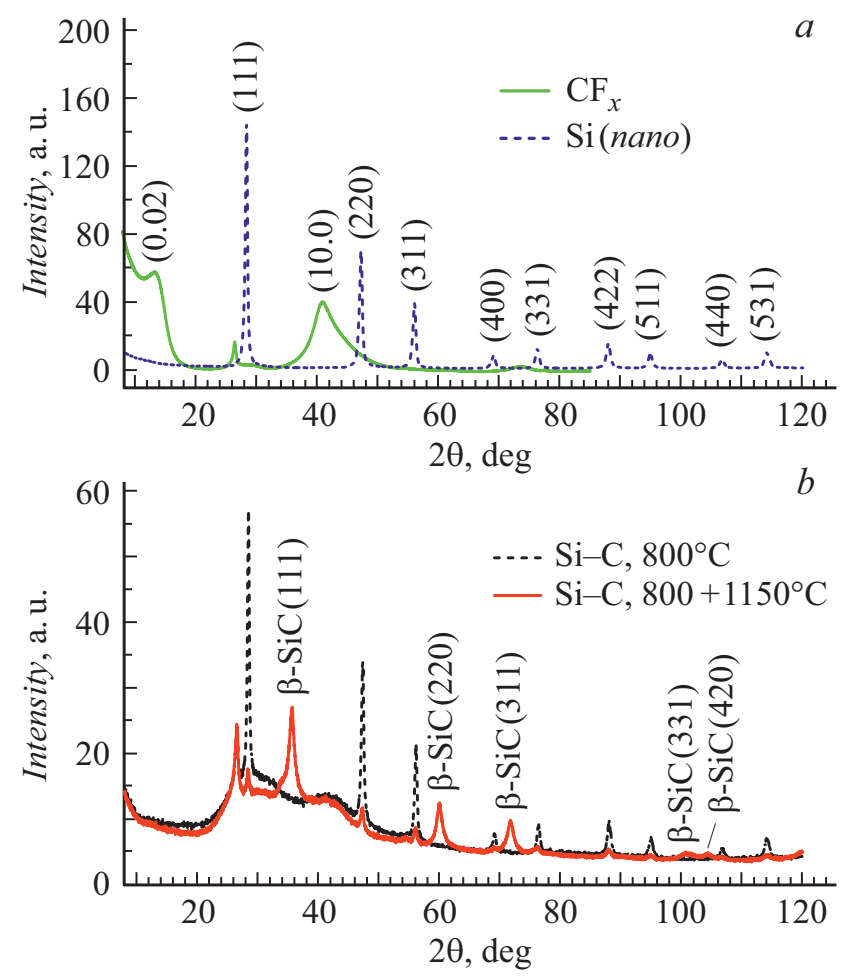

Рис. 2. Рентгеновские дифрактограммы исходных порошков нанокремния и фторуглерода $(a)$ и композита $\mathrm{Si}-\mathrm{C}$, изготовленного при $T=800^{\circ} \mathrm{C}$, и того же композита после дополнительного отжига при $1150^{\circ} \mathrm{C}(b)$. 
„полочки“ обусловлено колебаниями температуры в помещении, где проводились испытания (термостатирование отсутствовало). При снижении температуры происходит рост сопротивления ячейки (электрода и электролита), который приводит к тому, что установленное при заряде ограничение напряжения $10 \mathrm{mV}$ достигается за более короткое время, т.е. заряд уменьшается.

На рис. 1, $b$ построена зависимость разрядной емкости от температуры отжига в начале испытаний и на цикле 20 в области „полочки“. Видно, что резкое снижение емкости происходит для образцов, отожженных при $T \geqslant 1100^{\circ} \mathrm{C}$. В таблице приведены расчетные и измеренные значения емкости для образцов с разным содержанием кремния до и после дополнительного отжига.

Рентгенодифракционные исследования прекурсоров и полученных из них композитов проводились на порошковом дифрактометре D2 Phaser, Bruker ( $\mathrm{CuK}_{\alpha}$-излучение). Дифрактограммы анализировались с использованием программы DIFFRAC.EVA. На рис. 2, a показаны рентгенограммы исходных порошков нанокремния и фторуглерода. На рис. 2, $b$ приведены результаты дифракции для нанокомпозита, сформированного при $800^{\circ} \mathrm{C}$, и композита, подвергнутого дополнительному отжигу при $T=1150^{\circ} \mathrm{C}$. Для обоих образцов рефлексы, связанные с $\mathrm{CF}_{x}$, исчезли. Рефлексов углерода тоже не видно, что, по-видимому, связано с его аморфностью. Рефлексы от плоскостей кремния (см. JCPDS N 00-005-0565) в первом (сформированном при $800^{\circ} \mathrm{C}$ ) образце сохранились. Во втором образце интенсивность пиков кремния сильно снизилась, появились новые пики, совпадающие с известными линиями для кубического $\beta$-SiC (см. JCPDS N 00-0291129). Из этих данных следует, что в последнем случае бо́льшая часть кремния израсходовалась на образование $\mathrm{SiC}$.

Для исследования с помощью просвечивающей электронной микроскопии (ПЭМ) использовался микроскоп JEM 2100F (JEOL, Япония) при ускоряющем напряжении $200 \mathrm{kV}$. Отожженная таблетка измельчалась и диспергировалась в ультразвуковой ванне в течение $10 \mathrm{~min}$. Затем частицы полученного порошка помещались на поддерживающую медную сетку, покрытую пленкой графеноподобного углерода. Электронномикроскопические исследования проводились также с помощью растрового электронного микроскопа JSM $7001 \mathrm{~F}$ (JEOL, Япония).

На рис. 3, а представлено ПЭМ-изображение высокого разрешения для кремний-углеродного композита, подвергнутого отжигу при $1150^{\circ} \mathrm{C}$. На нем видны аморфные области (углерод), а также кристаллические области с разными межплоскостными расстояниями (кремний и карбид кремния). Показаны измеренные расстояния между плоскостями $d_{\mathrm{Si}}=3.13 \AA$ и $d_{\mathrm{SiC}}=2.53 \AA$. Их отношение $d_{\mathrm{Si}} / d_{\mathrm{SiC}}=1.24$ хорошо согласуется с отношением для известных постоянных

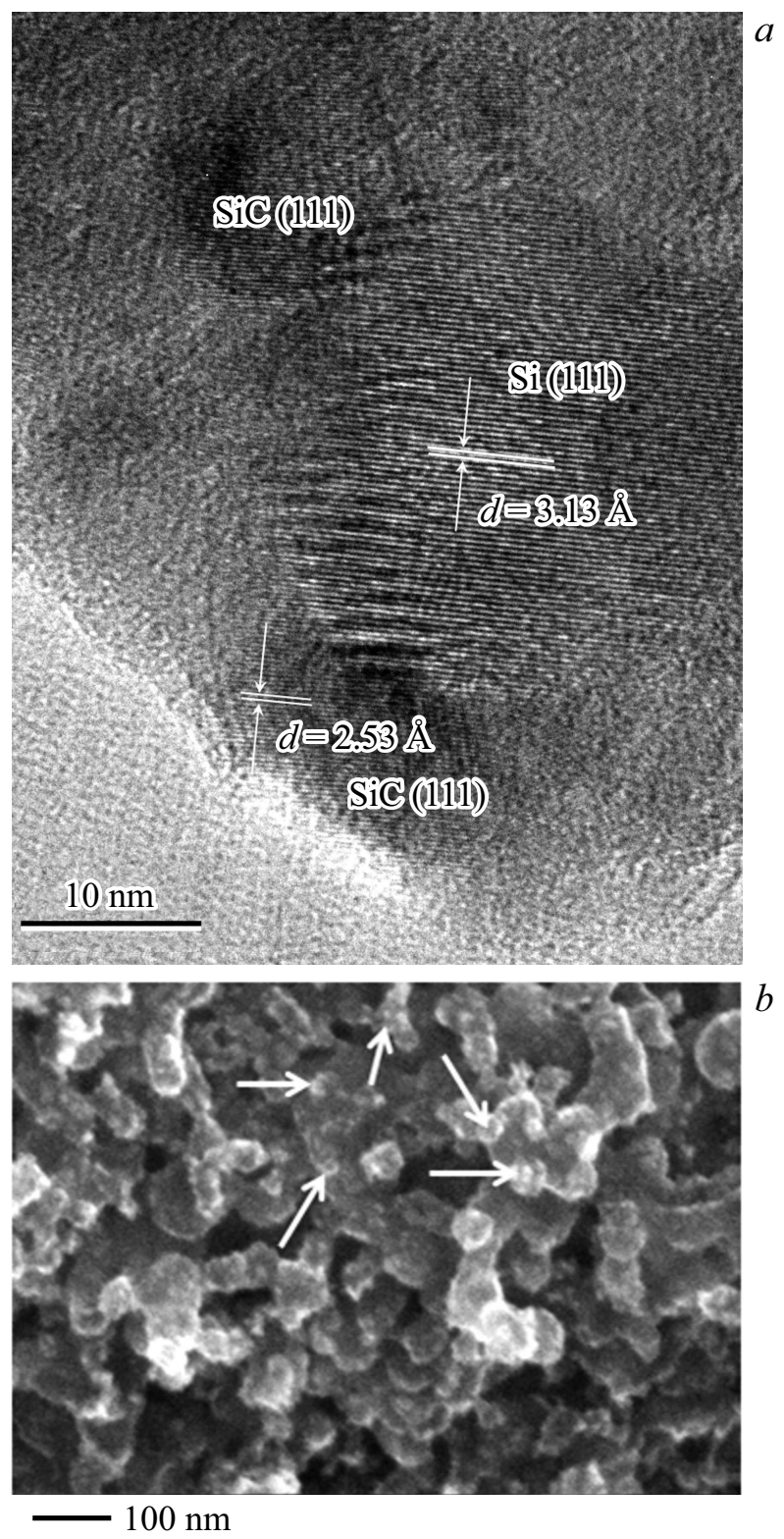

Рис. 3. Изображения композитов $\mathrm{Si}-\mathrm{C}$, отожженных при $1150^{\circ} \mathrm{C} . \quad a-$ в режиме высокого разрешения просвечивающего электронного микроскопа (композит с $34 \%$ $\mathrm{Si}) ; b-$ в сканирующем электронном микроскопе (композит с $52 \% \mathrm{Si}$ ), вид сверху (наночастицы, появившиеся на поверхности Si-зерен, выглядят как белые точки, некоторые из них обозначены стрелками).

решетки $a_{\mathrm{Si}} / a_{\mathrm{SiC}}=1.245\left(a_{\mathrm{Si}}=5.43 \AA, a_{\mathrm{SiC}}=4.36 \AA\right)$. Полученные значения

$$
d=\frac{a}{\sqrt{h^{2}+k^{2}+l^{2}}}=\frac{a}{\sqrt{3}}
$$

свидетельствуют о том, что наблюдаемые области отвечают плоскостям (111) для решеток кремния и кубического политипа карбида кремния $\beta$-SiC соответственно. На изображении в растровом электронном микроскопе 
Сравнение разрядной емкости для образцов разного состава до $\left(800^{\circ} \mathrm{C}\right)$ и после $\left(1150^{\circ} \mathrm{C}\right)$ дополнительного отжига для цикла 1 и в области ,полочки“ (циклы 20 и 76)

\begin{tabular}{|c|c|c|c|c|c|c|c|c|}
\hline \multirow{2}{*}{$\begin{array}{c}\mathrm{CF}_{x}, \\
\%\end{array}$} & \multirow{2}{*}{$\begin{array}{c}\mathrm{Si} \text { в } \\
\mathrm{Si}-\mathrm{C}, \\
\%\end{array}$} & \multirow{2}{*}{$\begin{array}{c}Q_{\text {calc }} \\
\mathrm{mA} \cdot \mathrm{h} / \mathrm{g}\end{array}$} & \multicolumn{6}{|c|}{$Q, \mathrm{~mA} \cdot \mathrm{h} / \mathrm{g}$} \\
\hline & & & $\begin{array}{l}\text { Номер } \\
\text { цикла }\end{array}$ & $800^{\circ} \mathrm{C}$ & $1150^{\circ} \mathrm{C}$ & $\begin{array}{c}\text { Номер } \\
\text { цикла }\end{array}$ & $800^{\circ} \mathrm{C}$ & $1150^{\circ} \mathrm{C}$ \\
\hline 60 & 52 & 2100 & 1 & 1700 & 850 & 20 & 685 & 495 \\
\hline 70 & 34 & 1400 & 1 & 1134 & 423 & 20 & 930 & 275 \\
\hline 75 & 22 & 1100 & 1 & 859 & 446 & 76 & 600 & 274 \\
\hline
\end{tabular}

(рис. 3, b) видно, что в результате термообработки при $1150^{\circ} \mathrm{C}$ исходные сферические частицы кремния несколько увеличиваются в размере, а на их поверхности появляются более мелкие наросты, по-видимому наночастицы SiC.

Из таблицы и зависимостей, приведенных на рис. 1, следует, что по мере повышения температуры дополнительного отжига происходит снижение как начального значения емкости $Q_{d c h}$ для цикла 1 , так и установившегося значения в области „полочки“. Для наиболее высокой из использованных температур отжига $\left(1150^{\circ} \mathrm{C}\right)$ емкость для композитов с малым содержанием Si (34 и $22 \%$ ) падает до очень малых значений $\sim 275 \mathrm{~mA} \cdot \mathrm{h} / \mathrm{g}$, что свидетельствует о том, что кремний практически полностью перестает аккумулировать литий. Образец, содержащий $52 \% \mathrm{Si}$, показывает лучшие результаты как по величине установившейся емкости $(\sim 500 \mathrm{~mA} \cdot \mathrm{h} / \mathrm{g})$, так и по стабильности при циклических испытаниях. Эксперименты, проводившиеся в работах $[9,10]$, указы вают на то, что сам по себе $\mathrm{Si}$-нанопорошок спекается при $T \geqslant 1100^{\circ} \mathrm{C}$, т.е. при температуре $1150^{\circ} \mathrm{C}$ этот процесс может происходить достаточно интенсивно и приводить к образованию более крупных зерен $\mathrm{Si}$. Однако в композитах с большим количеством углерода кремниевые частицы покрыты углеродной оболочкой, которая препятствует спеканию. По-видимому, в таких композитах после дополнительного высокотемпературного отжига бо́льшая часть кремниевых наночастиц превращается в $\mathrm{SiC}$, неактивный по отношению к литию. В случае меньшей концентрации углерода (52\% $\mathrm{Si}$ ) часть кремниевых наночастиц сохраняется, и они могут укрупниться за счет спекания. Наночастицы $\beta$-SiC, образовавшиеся в богатых кремнием анодах, могут способствовать более высокой устойчивости к деградации как за счет повышения механической прочности материала [11], так и за счет того, что они выполняют роль буферной матрицы при внедрении и экстракции лития [12].

Таким образом, проведенные эксперименты указывают на то, что образование карбида кремния в нанокомпозитах $\mathrm{Si}-\mathrm{C}$ происходит уже при температуре $\sim 1100^{\circ} \mathrm{C}$. Кубический политип карбида кремния даже в виде наночастиц неактивен при электрохимическом литировании, а его образование приводит к уменьшению емкости, внедряемой в композитный электрод $\mathrm{Si}-\mathrm{C}$.

\section{Благодарности}

Исследования проведены с использованием оборудования Центра коллективного пользования „Материаловедение и диагностика в передовых технологиях“ при ФТИ им. А.Ф. Иоффе РАН. Авторы благодарят М.А. Яговкину за помощь в анализе дифрактограмм.

\section{Финансирование работы}

Работа выполнена в рамках государственного задания ФТИ им. А.Ф. Иоффе в области фундаментальных научных исследований.

\section{Конфоликт интересов}

Авторы заявляют, что у них нет конфликта интересов.

\section{Список литературы}

[1] Liu Y., Zhou G., Liu K., Cui Y. // Acc. Chem. Res. 2017. V. 50. P. 2895-2905.

[2] Liu X., Zhu X., Pan D. // Roy. Soc. Open Sci. 2018. V. 5. P. 172370.

[3] Timmons A., Todd A.D.W., Mead S.D., Carey G.H., Sanderson R.J., Mar R.E., Dahn J.R. // J. Electrochem. Soc. 2007. V. 154. P. A865-A874.

[4] Son I.H., Park J.H., Kwon S., Park S., Rümmeli M.H., Bachmatiuk A., Song H.J., Ku J., Choi J.W., Choi J.-M., Doo S.-G., Chang H. // Nature Commun. 2015. V. 6. P. 7393.

[5] Kumari T.S.D., Jeyakumara D., Kumar T.P. // RSC Adv. 2013. V. 3. P. $15028-15034$.

[6] Li H., Yu H., Zhang X., Guo G., Hu J., Dong A., Yang D. // Chem. Mater. 2016. V. 28. P. 1179-1186.

[7] Sun X., Shao Ch., Zhang F., Li Y., Wu Q.-H., Yang Y. // Front. Chem. 2018. V. 6. P. 166.

[8] Астрова Е.В., Улин В.П., Парфеньева А.В., Воронков В.Б. // Письма в ЖТФ. 2019. Т. 45. В. 13. С. 29-32.

[9] Астрова Е.В., Воронков В.Б., Нащекин А.В., Парфеньева А.В., Ложскина Д.А., Томкович М.В., Кукушкина Ю.А. // ФТП. 2019. Т. 53. В. 4. С. 540-549. 
[10] Астрова Е.В., Воронков В.Б., Румянщев А.М., Нащекин А.В., Парфеньева А.В., Ложкина Д.А. // Электрохимия. 2019. Т. 55. № 3. С. 318-328.

[11] Tiegs T. Handbook of ceramic composites. N.Y.: Kluwer Academic Publ., 2005. P. 307-325.

[12] Jeon B.J., Lee. J.K. // J. Alloys Compd. 2014. V. 590. P. $254-$ 259. 